\title{
Erken Çocukluk Döneminde Uygulanan Çevre Eğitim Programının Çocukların Çevreye Karşı Tutumları Üzerindeki Etkisi
}

\section{Simge YILMAZ*， Emine YILMAZ-BOLAT**， İlknur GÖLCÜK***}

Öz: Bu çalışmanın amacı okul öncesi dönemdeki çocukların çevreye yönelik tutumlarını, çevreyi koruma, geri dönüşüm, tüketim alışkanlıkları ve yaşam alışkanlıkları alt boyutları ile araştırmaktır. Araştırmanın çalışma grubu, Mersin ili Yenişehir ilçesinde Milli Eğitim Bakanlığı'na bağlı bağımsız devlet anaokullarına ve anasınıflarına devam eden 54-60 aylık çocuklardan tesadüfi örnekleme yolu ile seçilen 71 çocuktan oluşmaktadır. Araştırmanın deseni, deneysel yöntemlerden tek grup ön-test son-test modeli olarak belirlenmiştir. Bu desene göre, katılımıcıların her biri ile ön-testin uygulanması, çevre eğitim programının uygulanması ve son-testin uygulaması, sırasıyla gerçekleştirilmiştir. Araştırmanın veri toplama materyali 'Çocukların Çevre Tutumları Ölçeği-Okul Öncesi Versiyonu'dur. Veriler her bir katılımcı ile birebir görüşmeler yapılarak toplanmıştır. Veri toplama materyalindeki 15 maddenin her biri ile ilgili soru, çocuklara maddelerin içeriğinin tasvir edildiği resimler gösterilerek sorulmuş ve çocukların yanıtları kaydedilmiştir. Araştırma kapsamında uygulanacak çevre eğitimi programının süresi dört hafta olarak belirlenmiştir. Çevre eğitimi, haftada bir gün farklı alanlara yapılan alan gezileri ve burada yapılan etkinliklerle uygulanmıştır. Katılımcıların çevreye yönelik tutumları, çevre eğitim programı uygulaması öncesinde ve sonrasında ölçülmüştür. Araştırma bulgularına göre, dört haftalık çevre eğitim programının, okul öncesi dönem çocuklarının çevreye yönelik tutumları üzerinde etkili olmadığı bulunmuştur. Çalışmanın bulguları tartışılarak, ileride yapılacak olan çalışmalara önerilerde bulunulmuştur.

Anahtar Kelimeler: Okul öncesi eğitimi, Çevre eğitimi, Çevreye yönelik tutumlar, Çevre eğitim programı, Tek grup ön-test son-test deseni

\footnotetext{
* Dr. Arş. Gör. Mersin Üniversitesi Eğitim Fakültesi, Temel Eğitim Bölümü, ORCID No: 0000-0002-50928670e-mail: simgeyilmaz@mersin.edu.tr

${ }^{* *}$ Doç. Dr. Mersin Üniversitesi Eğitim Fakültesi, Temel Eğitim Bölümü, ORCID No: 0000-0002-1062-4752 e-mail: emineyilmaz@mersin.edu.tr

Müdür Yardımcısı, Mersin Şevket Pozcu Anaokulu, e-mail: ilknurgolcukk@gmail.com
} 


\section{The Impact of an Early Childhood Environmental Education Program on Children's}

\section{Attitudes toward Environment}

Abstract: The aim of the current research is to investigate preschool children's attitudes toward environment, including environmental protection, recycle, consumption habits, and living habits. The participants of the research are 71 54-60-month-old children who has been randomly selected from public preschools and kindergartens affiliated to Ministry of National Education in Mersin. The research design was determined as one group pre-test post-test model which is one of the experimental design models. According to this model, each participating children was implemented the pre-test, the environmental education program and the post-test, respectively. The Children's Attitudes toward the Environment Scale-Preschool Version, CATES-PV, was used as a data collection material. The data was collected by the participants through one-to-one interviews. Questions about each of the 15 items in the data collection material was asked children with the accompany of the pictures representing each item and children's responses are recorded. The length of the environmental education program to be implemented in the scope of this research was determined as four weeks. The environmental education program was implemented with the field trips arranged to different places once a week. The participants' attitudes toward environment were measured before and after of the implementation of the environmental education program. According to the research findings, four-week environmental education program did not affect preschool children's attitudes toward environment. The findings of the research were discussed and the suggestion for the further research are included.

Key words: Early childhood education, Environmental education, Attitudes toward environment, Environmental education program, One group pre-test post-test design

\section{Giriş}

Günümüzde hızlı nüfus artışı ve teknolojik ilerlemeler nedeniyle çocuklar, küresel ısınmanın, biyoçeşitlilikte azalmanın, toprak erozyonunun, doğal yiyecek kaynağında azalmanın, enerji ve su kıtlığının ve hem insanların hem de doğanın sağlığını tehdit eden daha birçok çevre probleminin olduğu bir dünyaya doğmaktadırlar (Diamond, 2011; Gunderson, 2014). Bu problemlerin temel kaynağının insan davranışları olduğu bilinmektedir (Koger, 2013). Sanayileşme ile birlikte, ekonomik büyümenin egemen olması ve bunun insanların düşünüş biçimlerini büyük ölçüde etkilemesi, bireylerin yaşadıkları topluma ve üretime 
yabancılaşması, mutluluğun ihtiyaç dışı tüketimde aranması gibi durumlar toplumlar arasında yaygınlaşmış ve toplumları sosyal ve kültürel olarak kendilerini sorgulamaya sevk etmiştir (Dilek-Eren, 2014).

İnsanın doğa üzerindeki egemenliğini ve bunun yarattığı kötü sonuçları gözler önüne seren birçok bilim insanı ve yazar, var olan durumu ortaya koyarak, bu ciddi problemler ile ilgili adım atılması gerektiği konusunda bir farkındalık uyandırmaya çalışmıştır. Örneğin, Rachel Carson, Sessiz İlkbahar (Silent Spring, 1962) ve Merak Duygusu (Sense of Wonder, 1956) adlı eserlerinde, insanların doğayı kendi yararlarına ve amaçlarına uygun bir şekilde kullanmalarının doğuracağı olumsuz durumlardan bahsederek, bunun aksine doğayı tanımanın, doğa ile yakınlaşıp, bağ kurmanın öneminin altını çizmiştir. Bunu destekler biçimde, Jacques Ellul da teknolojinin insan türü üzerindeki olumsuz etkilerini anlattığı eserlerinde (Teknoloji Toplumu, The Technological Society, 1964) temel olarak, teknolojinin insan doğasına aykırı yönlerini dikkat çekici bir biçimde vurgulamıştır.

İnsanların ve insan uğraşı ile gelişen teknolojilerin yaşamın sonunu getirebilecek ciddi problemlere yol açması, var olan üretim ve tüketim sistemlerinin sorgulanmasının gerekliliğini düşündürmüştür. Çevrebilimcinin Yaşam Şablonu (The Ecologist's Blueprint of Survival, 1972), Küçük Güzeldir (Small is Beautiful, 1974) gibi çalışmalar ile Büyümenin Sınırları (The Limits to Growth, 1972) ve Ortak Geleceğimiz (Our Common Future, 1987) gibi raporlar, çevre problemlerinin ciddiyeti ile ilgili adımlar atılması gerektiği konusunda öncü olmuş ve çözüm yolları ile ilgili önemli uyarılarda bulunmuştur (Keleş ve Hamamcı, 1993). Bu öncü çalışmalarda temel olarak, insan çıkarının gözetilmediği çevre politikalarının geliştirilmesinin önemine ve bu amaçla hukuksal, eğitsel ve teknolojik adımlar atılmasının gerekliliğine vurgu yapılmıştır.

20. yüzyıldan itibaren çevre sorunları sadece ülkeleri ilgilendiren bir konu olmaktan çıkmış olup, küresel ölçekte bütün ülkelerin ortak meselesi haline gelse de; küresel 1sınma, iklim değişikliği, ozon tabakasının delinmesi, su ve hava kirliliği gibi problemler, günümüzde de insanın ve doğanın sağlığını tehdit eden ciddi çevre problemleri arasında sayılmaya devam etmektedir (Sonneld ve Mol, 2002). Temelini Birleşmiş Milletler Çevre ve Kalkınma Komisyonu'nun 1987 yılında yayımladığı Brutland Raporu'nun (Ortak Geleceğimiz) ve 1992 yılında Çevre ve Kalkınma Konferansı sonucunda yayımlanan Rio Deklerasyonu'nun oluşturduğu, 1994 yılında gerçekleşen Dünya Nüfus ve Kalkınma Konferansı, 2002 yılında Johannesburg'da gerçekleşen Birleşmiş Milletler Dünya Sürdürülebilir Kalkınma Zirvesi, 2015 yılında imzalanan Paris İklim Antlaşması, ve 2019 yılında New York’ta gerçekleşen Birleşmiş 
Milletler İklim Zirvesi uluslararası düzeyde çevre problemlerine yönelik yapılan çalışmalara örnek gösterilebilir.

Çevrebilimcinin Yaşam Şablonu (The Ecologist's Blueprint of Survival) ) çalışmasında Allen, Allaby, Davoll ve Lawrence'ın da belirttiği gibi eğitim, çevre problemleriyle baş edebilmenin en iyi yollarından biri olarak kabul edilmektedir (1972). Birçok araştırmacı, var olan kaynakların gelecek nesillere aktarılması olarak özetlenebilecek sürdürülebilir gelişmenin sağlanabilmesinde, özellikle çevre eğitiminin değerini ve önemini belirtmiştir (Otto ve Kaiser, 2014; Otto, Kaiser ve Arnold, 2014).

Pek çok beceri ve tutum gibi, çevre hakkında bilgi kazanımı ve çevreye karşı tutumların gelişimi de erken çocukluk döneminde şekillenmeye başlamakta ve daha sonraki yıllarda bireylerin çevre ile ilgili davranışlarını uzun soluklu olarak etkilemektedir (GrodzinskaJurzcak, Stepska, Nieszporek ve Bryda, 2006; Taşkın ve Şahin, 2008). Çevre farkındalığı gelişmiş, çevre konularında duyarlı ve çevreyi koruyan nesillerin yetişmesinin, iyi planlanmış, sürekli uygulanan erken çocukluk çevre eğitim programları ile gerçekleşebileceğini söylemek mümkündür (Potter, 2010; Wells ve Lekies, 2006). Ogelmen'e (2012) göre, Türkiye gibi gelişmekte olan ülkeler, çevre problemlerine yönelik en önemli çözümlerden biri olan çevre eğitim programlarını küçük yaştaki çocuklarla etkili bir şekilde uygulayarak, hem okul öncesi eğitimin kalitesini yükseltebilir, hem de çocukların çevre farkındalığını artırarak çevre problemlerine çözüm üretmede adım atmış sayılabilirler.

Yaşamın ilk yıllarından başlayarak çocuklarda çevre bilinci oluşturmak, çocukların doğal çevre ile olumlu etkileşimlerde bulunmasını sağlamak ve onların doğa ile bağlarını güçlendirmek mümkündür (Başal, 2015). Küçük yaşlarda çevre eğitimi ile çocuklar bilimsel süreç becerilerini etkili bir şekilde kullanmayı, iyi bir gözlemci olmayı, bilgiyi kendilerinin yapılandırabilecekleri deneyimler kazanmayı gerçekleştirebilirler (Russo, 2001). Birçok araştırmacı (örn: Solomon ve Heide, 2005), çevre ile etkileşimde bulunmanın bireylerin bütünsel gelişimini olumlu yönde etkilediğini ve stresle başa çıkmalarına yardımcı olabileceğini de vurgulamaktadır. Erken çocukluk döneminde etkili çevre eğitimi, çocukların gelişimlerine uygun olarak hazırlanan bilgi temelli ve bu bilgiyi yine çocukların kendilerinin yapılandırmalarına fırsat veren aktif katılımlı gerçek ortamlarda etkili olmaktadır (Cohen, 1994).

Pek çok araştırmacı çocukların çevre ile ilgili fen kavramlarını nasıl algıladıklarını, özellikle bilgilendirici çevre eğitimi programları yoluyla çocukların tutum ve davranışlarında ne gibi değişiklikler gözlemlenebileceğini araştırmıştır (Bonnet ve Williams, 1998; Boyes ve 
Stanisstreet, 1993). Araştırma bulguları, çocukların çevre ile ilgili bilgilerinin ve çevreye karşı tutumlarının erken çocukluk döneminde şekillendiğini, çevre farkındalığı gelişmiş çocukların yaşamlarının ileriki dönemlerinde çevreye karşı olumlu tutum besleyen ve sorumlu bireyler olacaklarını vurgulamaktadır (Basile, 2000; Grodzinska-Jurzcak, Stepska, Nieszporek ve Bryda, 2006; Smith, 2001; Turtle, Convery, ve Convery, 2015; Wilson, 1996). Ayrıca, çevre eğitim programlarının yapılandırmacı eğitim yaklaşımı ile hazırlanmasının da, çocukların çevreyi sevmeleri, çevreye saygı duymaları ve çevreyi korumaları ile ilgili tutum ve davranışlarını olumlu etkilediği belirtilmiştir (Ballantyne ve Packer, 1996; Wilson, 1993).

Handler ve Epstein'e (2015) göre, küçük yaşlarda kazanılan çevre bilincinin yaşamın devam eden yıllarında sürdürülebilmesi, bu yaşlarda özgür bir şekilde ve doğal ortamlarda deneyim kazanılması ile gerçekleşebilmektedir. İnformal eğitim ortamlarında uygulanan çevre eğitim programlarının çocuklarda çevresel farkındalık (Erdoğan ve Uşak, 2009), çevre bilinci (Erdoğan ve Mısırlı, 2007) ve çevreye karşı sorumlu olma (Matthews ve Riley, 1995) gibi durumlara katkı sağladığı ve bu durumların da çevreye karşı olumlu tutum ve davranış geliştirmede etkili olduğu bilinmektedir (Dresner ve Gill, 1994). Çevre eğitiminin formal eğitim ortamları dışında, parklar, müzeler, hayvanat bahçeleri, akvaryumlar, orman/ağaçlık alan veya doğa merkezleri gibi informal okul dışı eğitim ortamlarına düzenlenebilecek alan gezileri ile de gerçekleştirilebileceği son yıllarda ilgi gören bir yaklaşımdır (Aktaş-Arnas, 2019; Heimlich, 2010). Okul dışında uygulanan çevre eğitim programları çocuklar için sınıf içinde çevre eğitimi ile ilgili yapılan uygulamalardan daha çekicidir; çünkü çocuklar okul dışı ortamlarda yoğun bir şekilde çevreyi keşfetme ve farklı deneyimler kazanma firsatı bulurlar (Falk, 2001). Bu deneyimler çoğu zaman çocuğun duygusal gelişimini destekler niteliktedir (Stone ve Glascott, 1998). Çevre eğitiminin uygulanmasını sağlayan kişiler olarak öğretmenlerin, çocukların çevre hakkında bilgi edinmeleri ve çevre problemlerinin çözümü için harekete geçmelerinin formal okul ortamlarında kolay ve anlamlı olmadığını düşünmeleri de, çevre eğitim uygulamalarının bahsedilen okul dışı öğrenme ortamlarındaki etkililiğini göz önüne sermektedir (Stevenson, Brody, Dillon ve Wals, 2013).

Özellikle farklı ortamlarda gerçekleştirilmiş çevre eğitim programlarının etkisinin araştırıldığı çalışmalar, genellikle ilköğretim veya ortaöğretim seviyesindeki öğrencilerle gerçekleştirilmiştir. Bu çalışmalarda özellikle açık alanlara düzenlenen gezilerin ve burada yapılan eğitimsel uygulamaların, çocukların aktif katılımını sağladığı ve yaparak yaşayarak öğrenmelerini desteklediği için, onların çevre ile ilgili kazanımlarında (olumlu davranış, tutum ya da algı) sınıf ortamında yapılan eğitim uygulamalarından çok daha fazla etkili olduğu 
bulunmuştur (Erdoğan ve Erentay, 2007; Erdoğan, Erentay, Barss ve Nechita, 2008; Erdoğan, 2011; Özdemir, 2010; Pekmez, Y1lmaz ve Kahveci, 2010; Starosta, 1990).

Alan yazında çevre eğitiminin çocuklar üzerindeki etkilerini neden-sonuç ilişkilerine dayandırarak açıklayan araştırmalara da rastlanmaktadır (Gülay, Yılmaz, Turan Güllaç ve Önder, 2010; Gülay-Ogelman, 2012; Gülay-Ogelman ve Durkan, 2014; Özdemir ve Uzun, 2006; Şallı, 2011; Şallı, Dağal, Küçükoğlu, Niran ve Tezcan, 2013; Tanrıverdi, 2012; Yalçın 2013; Yılmaz, Temiz ve Karaarslan-Semiz, 2018). Örneğin, Şallı ve diğerleri (2013), okul öncesi eğitim kurumlarına devam eden 30 çocuk ile yaptıkları ön-test son-test kontrol gruplu deneysel çalışmada, çocuklara aile katılımlı ve proje tabanlı bir program uygulayarak, çocuklarda geri dönüşüm kavramının kalıcılığını sağlamayı amaçlamışlardır. Araştırmanın bulgularına göre, çevre eğitim programının etkililiği istatistiksel olarak anlamlı bulunmuş olup, deney grubundaki çocukların kontrol grubundaki çocuklara göre geri dönüşüm kavramını daha iyi bir şekilde kazandıkları belirlenmiştir. Gülay-Ogelman ve Durkan (2014) ise okul öncesi eğitim kurumuna devam eden beş-altı yaşlarındaki 130 çocuğa toprak eğitim programı uyguladıkları yarı deneysel bir çalışma ile programın etkililiğini araştırmışlardır. Toprak eğitimi programı, içerik olarak çocuklara toprağın önemini ve yapısını, toprakta yaşayan canlıları, erozyonu ve nedenlerini anlatmayı ve çocukların çevreye karşı duyarlılıklarını artırmayı amaçlamıştır. Araştırma sonuçları, deney grubuna alınan çocukların toprak hakkındaki bilgilerinin programın etkisi ile arttığını göstermiştir.

Alan yazında ilgili çalışmalara bakıldığında, okul öncesi dönem çocukları ile yapılan deneysel çalışmaların az sayıda olduğu görülmüştür. Az sayıda yapılan bu araştırmalar arasında ise, tek grup ön-test son-test araştırma deseninin kullanımına rastlanmadığı ve çevre eğitim programlarının çocukların tutumlarını değiştirmedeki etkililiğin, okul öncesi eğitim seviyesinde yeterince araştırılmadığı belirlenmiştir. Bununla birlikte, küçük çocuklarla uygulanan çevre eğitim programlarının, okul dışı öğrenme ortamlarında gerçekleşmesi ve bu programların çocukların öğrenmeleri üzerindeki katkılarının araştırılması ile ilgili de sınırlı sayıda çalışma bulunduğu görülmüştür. Bu nedenle, bu araştırmada, okul öncesi dönem çocuklarının çevreye karşı tutumlarının tek grup ön-test son-test araştırma modeli kullanılarak araştırılması amaçlanmıştır.

$\mathrm{Bu}$ amaç doğrultusunda çalışmanın temel araştırma sorusu: Çevre eğitimi programına katılan okul öncesi eğitime devam eden 54-60 aylık çocukların çevreye yönelik tutumlarının ölçüldüğü ön test, son-test puan ortalamaları arasında istatistiksel açıdan anlamlı düzeyde farklılık var mıdır? Şeklinde belirlenirken; 
Araştırmanın alt araştırma soruları ise aşağıdaki gibi belirlenmiştir:

1) Okul öncesi eğitime devam eden 54-60 aylık çocukların ön-test son-test puan ortalamaları arasında çevreyi koruma ile ilgili tutumları bakımından istatistiksel olarak anlamlı bir farklılık var midır?

2) Okul öncesi eğitime devam eden 54-60 aylık çocukların ön-test son-test puan ortalamaları arasında tüketim alışkanlıkları bakımından istatistiksel olarak anlamlı bir farklılık var midır?

3) Okul öncesi eğitime devam eden 54-60 aylık çocukların ön-test son-test puan ortalamaları arasında geri dönüşüm ve yeniden kullanma bakımından istatistiksel olarak anlamlı bir farklılık var midır?

4) Okul öncesi eğitime devam eden 54-60 aylık çocukların ön-test son-test puan ortalamaları arasında yaşam alışkanlıkları bakımından istatistiksel olarak anlamlı bir farklılık var mıdır? olarak belirlenmiştir.

\section{Araştırma Modeli}

\section{Yöntem}

$\mathrm{Bu}$ araştırma okul öncesi eğitim kurumlarına devam eden 54-60 aylık çocukların çevreye karşı tutumlarını araştırmak amacıyla yapılmıştır. Araştırma, deneysel yöntemlerden tek grup ön-test son-test araştırma deseni ile gerçekleşmiştir. Bu modele göre, deneyden (örn., çevre eğitim programı uygulaması) önce ve sonra sırasıyla ön-test ve son-test ölçümleri yapılmaktır (Karasar, 2000). Katılımcılardan toplanan veriler bire bir görüşmeler yoluyla ve çevre konulu resim çalışmaları aracılığı ile toplanmıştır. Araştırmada kontrol grubunun olmamasının nedeni, araştırmanın proje kapsamında tek bir okuldaki 54-60 yaş aralığındaki çocuklarla yapılmış olması ve aynı yaş grubundan, aynı sayıda çocuğa ulaşılabilmesi için gerekli izin prosedürleri için gerekli zamanın kısıtlı olması ile ilgilidir.

\section{Evren ve Örneklem Grubu}

$\mathrm{Bu}$ araştırmanın evrenini Mersin ili merkez ilçelerinden Yenişehir ilçesindeki okul öncesi eğitim kurumlarına devam eden çocuklar oluşturmaktadır. Araştırmanın örneklemi ise Mersin ili merkez ilçelerinden olan Yenişehir ilçesindeki resmi anaokulu ve anasınıflarına devam eden 71 çocuktan oluşmaktadır. Örneklem belirlemesinde öncelikle Yenişehir ilçesinde Milli Eğitim Bakanlığı'na bağlı resmi anaokulu ve bünyesinde anasınıfı bulunan ilkokullara resmi yazı gönderilmiş olup, katılımcılar, gönüllü katılım sağlamak isteyen çocuklar arasından tesadüfi örnekleme yöntemiyle belirlenmiştir. $\mathrm{Bu}$ amaçla çalışmaya, birinci grupta 26, ikinci grupta 21 ve üçüncü grupta 24 çocuk olacak şekilde toplam 71 çocuk dâhil edilmiştir. Araştırma 
grupları oluşturulurken gruplar arasında demografik özellikler dikkate alınarak homojen bir dağglım sağlanmaya özen gösterilmiştir. Çalışma kapsamında araştırmaya dâhil olan çocuklar 54-60 ay aralığında olup, çalışmaya 34 kız ve 37 erkek çocuk dâhil olmuştur. Çocukların tamamı çalışma kapsamında tüm eğitimlere, ön-test ve son-test uygulamasına katılmıştır.

\section{Veri Toplama Araçları}

Araştırmada veri toplamak amacıyla Musser ve Diamond (1999) tarafından geliştirilmiş olan "Çocukların Çevre Tutumları Ölçeği-Okul Öncesi Versiyonu” (The Children's Attitudes toward the Environment Scale-Preschool Version, CATES-PV) kullanılmıştır. Bu ölçek Kahriman-Öztürk, Olgan, ve Tuncer (2010) tarafından Türkçeye uyarlanmıştır. Ölçek çevre ile ilgili tutumları, çevreyi koruma (bitkiler, böcekler ve diğer hayvanları koruma), tüketim alışkanlıkları (kâğıt, su, elektrik), geri dönüşüm ve yeniden kullanma ve yaşam alışkanlıkları (oyun alanı tercihleri, konut tercihleri) açısından değerlendiren 15 sorudan oluşmaktadır. Çocuklara bireysel görüşmelerde resimler gösterilerek sorular sorulmakta ve yanıtlar araştırmacı tarafından not edilmektedir. Görseller yardımı ile katılımcılara sorulan sorular, çocukların dişlerini firçalarken suyu açık bırakıp bırakmamaları, bir odadan çıkarken 1şı̆̆ kapatıp kapatmamaları, bir kağıda resim çizerken ya da yazı yazarken kağıdın her iki tarafını kullanıp kullanmamaları ile ilgili sorulardır. Ölçeğin geçerlik ve güvenirlik çalışmaları yapılmış olup geçerli ve güvenilir olduğu tespit edilmiştir. Ölçeğin güvenirliği Cronbach alpha katsayısı ile değerlendirilmiş olup, değeri .68 bulunmuştur. Ölçeğin geçerliği (yap1 geçerliliği) ise Bandura tarafından çocukların tutumlarının gözlemlerine ve deneyimlerine bağlı olduğunu belirten Sosyal Öğrenme Teorisi'ne dayanan çocuk ve ebeveyn arasındaki ilişki ile değerlendirilmiştir. Korelasyon sonuçları anneler için $\mathrm{r}(21)=.76, p<.0001$, ve babalar için $\mathrm{r}(20)=.60, p<.01$ bulunmuş olup ebeveyn tutumları ile çocukların tutumları arasında yüksek korelasyon olduğu belirtilmiştir (Musser ve Diamond, 1999). Yap1 geçerliliğine ek olarak, ölçeğin görünüş geçerliliği ile ilgili çalışmalar da yapılmıştır. Ölçek maddeleri ve resimleri beş uzman (üç okul öncesi eğitim uzmanı ve bir çevre eğitimi uzmanı ve bir İngilizce eğitimi uzmanı tarafından gözden geçirilmiştir ve gerekli değişiklikler bir okul öncesi eğitim uzmanının önerileri doğrultusunda araştırmacı tarafından yapılmıştır.

\section{Çevre Eğitimi Programı}

Çocukların çevreye karşı tutumlarının olumlu yönde geliştirilmesini hedefleyen çevre eğitim programı, öncelikle programa katılan tüm çocuklar, eğitimciler ve ailelerin katıldığı kukla ve animasyon gösterisi ile başlamıştır. Çevre eğitim programlarında ailelerin katılımının önemi yüksek olduğu için, çocuklarla yapılan ilk buluşmada ailelerin de dâhil olması, 
ebeveynlerin projenin amacını, sürecini, proje kapsamında ziyaret edilecek yerleri öğrenmeleri bakımından faydalı olmuştur. Buradaki asıl amaç, ebeveynleri projeni amacı ve süreci ile ilgili detaylar hakkında bilgilendirmek ve proje süresince yapılacak alan gezilerinde, açık alanda çocuklarla birlikte olacak yetişkin sayısını artırmak için ebeveynlerden destek alınmasını kolaylaştırmak olmuştur. İlk buluşmaya çocukların tamamının ebeveynleri katılmıştır. Daha sonra yapılacak alan gezilerine de bazı ebeveynler katılım sağlamıştır. İlk buluşmada gerçekleştirilen kukla gösterisi ve animasyon gösteriminde amaç çocuklarda çevreye yönelik farkındalık oluşturmak olmuştur. Proje kapsamında gerçekleştirilen ilk buluşmanın dışında, üç haftalık eğitim programı düzenlenmiş ve çevre eğitim programının uygulandığı toplam süre, dört hafta olarak belirlenmiştir. Çevre eğitimi ile ilgili uygulamalar ilk hafta tüm çocuklarda, eğitimcilerle ve ebeveynlerle gerçekleşirken, daha sonraki üç hafta, farklı alanlara düzenlenen gezilerle yapılmıştır. Son üç haftalık eğitimlerde, her üç gruptaki çocuklar alan gezilerini ve eğitimlerini haftanın farklı gruplarında tamamlamıştır. Eğitimlerin düzenlendiği alanların ilki Mersin iline bağlı Hebilli Köyü’nde bulunan bir solucan çiftliği olmuştur. Burada temel olarak solucanların yaşam alanları gözlenmiş, çocukların solucanları büyüteçle izlemelerine fırsat verilmiş ve organik solucan gübresi ile ilgili bilgi alınmıştır. Bir sonraki eğitim, Mersin ilinin Mezitli ilçesinde bulunan 100. Y1l (Gümüşkum) tabiat parkına düzenlenen bir gezi ile gerçekleştirilmiştir. Burada ağırlık verilen temel etkinlik çöp sorunu ile ilgili olup, çocukların çöplerle ilgili farkındalığının artması ve bu konuya ilişkin çözüm yolları üretmeleri amaçlanmıştır. Çocuklarla birlikte bu alanda çöp toplama etkinliği düzenlenmiştir. Bu parkta ayrıca çocukların caretta carettaları gözlemleyebilecekleri bir sahil ve deniz kaplumbağalarını koruma, rehabilitasyon, araştırma ve eğitim faaliyetlerinin yürütüldüğü bir merkez bulunmaktadır. Bu merkez ziyaret edilerek, çocuklara uzmanlar tarafından caretta carettalarla ilgili bilgiler verilmiş, çocukların bu hayvanları gözlemlemeleri sağlanmış ve çocukların tüketim ve yaşam alışkanlıklarının bu hayvanları nasıl etkileyebileceği, bu hayvanları nasıl korunabileceği ile ilgili bilinçlendirme amaçlı etkinlikler yapılmıştır. Son hafta gerçekleşen alan gezisi ise ÇEVDOSAN atık ayrıştırma ve geri dönüşüm tesisine yapılmıştır. İlgililer tarafından tesis çocuklara gezdirilip atıkların ayrıştırılması ve geri dönüşüm süreci ile ilgili bilgiler verilmiştir. $\mathrm{Bu}$ bilgilerin çocukların öğrenmesinde kalıcı hale gelebilmesi için, çocukların ayrıştırma ve geri dönüşüm kavramlarını somutlaştırabilecekleri düşünülerek, farklı atık maddeleri ayrıştırmaları ve geri dönüşüm kutularına uygun bir şekilde atmaları yönünde bir etkinliğe katılımları sağlanmıştır. 
Eğitimlerin gerçekleştirildiği ve gezilerin düzenlendiği her alan, çocuklarla birlikte ziyaret edilmeden önce eğitimciler tarafından ziyaret edilerek gerek eğitim alanının düzenlenmesi ile ilgili, gerekse orada iletişim kurulacak personellerle ilgili ön çalışmalar yapılmıştır.

\section{Verilerin Toplanması ve Analizi}

Görüşme soruları 2018-2019 eğitim-öğretim yılının bahar yarıyılında, araştırmaya katılan çocukların devam ettikleri okul öncesi eğitim kurumunda, araştırmacılara sağlanan sessiz bir odada uygulanmıştır. Görüşmeler projeye dahil olan araştırmacılar tarafından, her bir çocukla bire bir görüşme yolu ile gerçekleştirilmiştir. Resimler eşliğinde sorulan ve 15 sorudan oluşan “Çocukların Çevre Tutumları Ölçeği- Okul Öncesi Versiyonu” (CATES-PV), projeye katılan üç grup çocuğa da etkinliklere başlamadan önce ön-test ve etkinlikler bitiminde son-test olarak uygulanmıştır. Görüşmeler sırasında her bir çocuğa, her 15 görüşme sorusu için, çevreye karşı olumlu ve olumsuz tutum sergileyen 2 farklı davranış modeli resmi gösterilmiştir. Daha sonra araştırmacılar, görüşme yapılan her çocuğa, hangi modeldeki çocuk gibi davranış sergilediklerini sormuşlardır. Görüşme her bir çocukla yaklaşık $20 \mathrm{dk}$. sürmüştür. Uygulanan ölçekte puanlama çocukların cevaplarına göre her zaman seçeneği için "2” puan, ara sıra seçeneği için " 1 ” puan ve asla seçeneği için " 0 ” puan verilerek yapılmıştır. Ölçekten elde edilen verilerin analizinde SPSS paket programı kullanılmıştır. Verilerin analizine geçmeden önce toplanan veriler bilgisayar ortamında SPSS programına aktarılmış olup, verilerin genel değerlendirmesi yapılmıştır. Araştırma verilerinin analizine geçilmeden önce ölçeğin alt boyutlarının ve ön-test son-test toplam puan farkının normal dağılım gösterip göstermediği Shapiro Wilk testi ile değerlendirilmiştir (Kalaycı, 2010). Shapiro-Wilk testinin kullanılma nedeni grup büyüklüklerinin 50'den küçük olmasıdır (Büyüköztürk, 2010).

Shapiro Wilk testi sonuçlarına göre ölçeğin alt boyutlarının hiç biri normal dağılım göstermemiştir. Bu nedenle bu kısımların analizinde parametrik olmayan testlerden KruskalWallis testi kullanılmıştır. Yine bu testin sonucuna göre ön-test son-test toplam puan fark1 normal dağılım gösterdiği için, bu sonuçların analizinde ilişkili ölçümlerde ortalama puanların karşılaştırıldığı t-test kullanılmıştır.

\section{Bulgular ve Tartışma}

$\mathrm{Bu}$ bölümde araştırmaya ilişkin bulgular ve bulgulara ilişkin tartışma kısmı bulunmaktadır. 
Araştırmaya katılan grupların her bir alt boyutunun ve toplam testin ön-test ve son-test puanlarının normal dağılım gösterip göstermediği Shapiro Wilk testi ile değerlendirilmiş olup sonuçlar Tablo 1'de sunulmuştur.

Tablo 1.

Araştırmaya Katılan Tüm Grupların Ölçeğin Alt Boyutlarına ve Ön-Test Son-Test Toplam Puan Farklarına İlişskin Normallik Dağılımları

\begin{tabular}{lccc}
\hline & Normallik Testi & & \\
& \multicolumn{3}{c}{ Shapiro-Wilk } \\
\cline { 2 - 4 } & \multicolumn{1}{c}{ İstatistik } & df & Sig. $(p)$ \\
\cline { 2 - 4 } Ön-test geri dönüşüm &, 838 & 70 &, 000 \\
Son-test geri dönüşüm &, 650 & 70 &, 000 \\
Ön-test çevre koruma &, 910 & 70 &, 000 \\
Son-test çevre koruma &, 872 & 70 &, 000 \\
Ön-test tüketim alışkanlıkları &, 938 & 70 &, 002 \\
Son-test tüketim alışkanlıkları &, 921 & 70 &, 000 \\
Ön-test yasam alışkanlıkları &, 936 & 70 &, 001 \\
Son-test yaşam alışkanlıkları &, 857 & 70 &, 000 \\
Ön-test toplam puan &, 970 & 70 &, 089 \\
Son-test toplam puan &, 970 & 70 &, 086 \\
Toplam fark &, 981 & 70 &, 366 \\
\hline
\end{tabular}

Çalışmaya katılan her üç gruptaki çocukların, ölçeğin alt boyutları olan geri dönüşüm, çevreyi koruma, tüketim alışkanlıkları ve yaşam alışkanlıkları ile ilgili ön-test ve son-test puanları için hesaplanan $p$ değeri $<.05$ olduğu için anlamlılık düzeyinde puanların normal dağılım göstermediği bulunmuştur. Bununla birlikte, ön-test son-test toplam puanları ve toplam puan farkları için hesaplanan $p$ değeri > .05 olduğu için anlamlılık düzeyinde puanların normal dağılım gösterdiği bulunmuştur. $\mathrm{Bu}$ nedenle alt boyutlar Kruskal-Wallis testine göre değerlendirilirken, toplam ön-test son-test puan farkları t-test kullanılarak değerlendirilmiştir. Tablo 1 de sunulan sonuçlara göre, Tablo 2 Kruskal-Wallis testi sonuçlarını gösterirken, Tablo 3 ise ilişkili ölçümlerde ortalama puanların karşılaştırıldığ 1 t-test sonucunu göstermektedir. 


\section{Tablo 2.}

Katılımcıların Ön-Test Son-Test Toplam Ölçek Puanlarına İlişkin Kruskal-Wallis Testi Sonuçları

\begin{tabular}{lrrrr}
\hline \multicolumn{5}{c}{ Kruskal-Wallis testi } \\
\hline & Çevre koruma & Geri dönüşüm & $\begin{array}{c}\text { Tüketim } \\
\text { alı̧kanlıkları }\end{array}$ & Yaşam alışanlıkları \\
\hline Ki kare $\left(X^{2}\right)$ & 1,015 & 1,905 &, 590 & 3,029 \\
df & 2 & 2 & 2 & 2 \\
Asymp. Sig. $(p)$ &, 602 &, 386 &, 745 &, 220 \\
\hline
\end{tabular}

Çocukların çevreye karşı tutumlarının çevreyi koruma, geri dönüşüm, tüketim alışkanlıkları ve yaşam alışkanlıkları alt boyutlarından aldıkları ön-test son-test puanlarına göre anlamlı farklılık gösterip göstermediğini belirlemek amacı ile yapılan Kruskal-Wallis testi sonucuna göre, çocukların toplam ön-test son-test puanları arasında istatistiksel olarak anlamı bir fark bulunmamaktadır. Çocukların çevreye yönelik tutumları, çevreyi koruma alt boyutunda $(p=.60)$, geri dönüşüm alt boyutunda $(p=.39)$, tüketim alışkanlıkları alt boyutunda $(\mathrm{p}=.74)$ ve yaşam alışkanlıkları alt boyutunda $(p=.22)$ olarak bulunmuştur. Bu değerler, belirlenen istatistiksel anlam eşiğinin $(p<.05)$ üzerinde değerler olduğu için, istatistiksel olarak anlamlı bir fark yaratmadığı görülmüştür. Sonuç olarak, uygulanan çevre eğitimi programının çocukların çevreye yönelik tutumları üzerinde etkili olmadığı bulunmuştur.

Çevre eğitim programları çocukların tutum ve davranışları üzerinde kısa ya da uzun vadede etkili olabilir ve değişikliğe neden olabilir (Gülay, 2011). Bu çalışma kapsamında çevre eğitim programının çocukların çevreye yönelik tutumları üzerinde etkili olmaması ise, programın uygulama süresinin kısıtlılığı ile açıklanabilir. Erken çocukluk döneminde çocukların tutum ve davranışlarında değişiklik yaratmanın zaman alıcı olabileceği düşünülerek, sürekli ve düzenli hazırlanan çevre eğitimi programları, erken çocukluk eğitimi programlarının bir parçası haline gelmelidir (Gülay ve Ekici, 2010). Çocukların tutum ve davranışlarının değişebilmesi için özellikle çevre eğitimi kapsamında yapılacak olan uygulamaların uzun soluklu, birbirini takip eden, çocukların hazırbulunuşluklarını önemseyerek var olan bilgilerine yenilerini eklemelerini destekleyen programlar olmasına özen gösterilmelidir.

Tablo 3. 
Katılımcıların Ön-Test Son-Test Toplam Ölçek Puanlarına Göre İlişkili Ölçümlerde Ortalama Puanların Karşılaştırıldığı T-Testi Sonuçları

\begin{tabular}{lrrcccc}
\hline \multicolumn{7}{c}{ İlişkili gruplar t-testi } \\
\hline & $\overline{\mathrm{X}}$ & $\mathrm{N}$ & $\begin{array}{c}\text { Standart } \\
\text { Sapma }\end{array}$ & $\begin{array}{c}\text { Standart hata } \\
\text { ortalama }\end{array}$ & $\mathrm{t}$ & $p$ \\
\cline { 2 - 6 } ön-test toplam puan & 19,12 & 71 & 3,71456 &, 44084 & $-1,961$ & 0,054 \\
& 68 & & & & & \\
son-test toplam puan & 20,12 & 71 & 3,98185 &, 47256 & & \\
68 & & & & \\
\hline
\end{tabular}

İlişkili gruplar t-testi, katılımcılara uygulanan çevre eğitim programının çocukların çevreye yönelik tutumları üzerinde etkili olup olmadığını belirlemek amacıyla yapılmıştır. Bu test ile grupların 'Çocukların Çevre Tutumları Ölçeği-Okul Öncesi Versiyonu' testinden aldıkları puanlar kendi içlerinde kıyaslanmıştır.

İlişkili gruplar t-testi sonuçlarına göre, çocukların ön-test ortalama puanları 19,13; standart sapmaları 3,71 iken, son-test ortalama puanları 20,13, standart sapmaları ise 3,98'dir. Çocukların uygulama öncesi ve uygulama sonrası toplam puanları arasında sadece bir puanlık bir artış görülmüştür ve bu artış istatistiksel olarak anlamlı bir fark yaratmamıştır $\left(\mathrm{t}_{(70)}=.054 ; p\right.$ $>$.05). Sonuç belirlenen istatistiksel anlam eşiğine göre değerlendirildiğinde, uygulanan çevre eğitim programının çocukların çevreye yönelik tutumlarını etkilemediği söylenebilir.

Bu sonuçlar literatürdeki farklı çalışmalarla karşılaştırıldığında (örn: Gülay-Ogelman ve Durkan, 2014; Şallı vd., 2013), bu çalışma kapsamında çocukların yeterli sayıda aktiviteye dahil olarak, yeterince yaparak yaşayarak öğrenme firsatı elde edemediği ve eğitim süresinin çocukların çevreyi koruma, geri dönüşüm, tüketim alışkanlıkları ve yaşam alışkanlıklarını değiştirmek için yeterli olmadığı söylenebilir. Ayrıca, proje kapsamında çocukların çevreye yönelik tutumlarında çevre eğitim programının etkisinin olmaması, öğretmenlerin eğitim süresinde okullarında devam eden eğitim uygulamalarındaki eksiklikler ile açıklanabilir. Programa katılan çocukların öğretmenleri, çevre eğitim programı kapsamında yapılan uygulamaları, sınıf ortamında ya da farklı açık alanlarda yapılabilecek farklı türdeki aktivitelerle desteklemek konusunda yetersiz kalmış olabilirler. Gülay (2011) çevre eğitimi ile ilgili yapılan çalışmaların etkili olabilmesi için, konuların ve öğretim yöntemlerinin çeşitlendirilerek çocuklara sunulmasını önermiştir. Bu çalışma kapsamında, öğretmenlerin 
çevre eğitimi programına katılımları dışındaki öğretim etkinliklerinin, çocukların öğrenmelerini pekiştirmesi bakımından yetersiz kaldığı söylenebilir.

\section{Sonuç ve Öneriler}

Bu çalışmada, okul öncesi eğitime devam eden 54-60 aylık çocuklara informal eğitim ortamlarında devam eden dört haftalık çevre eğitim programı uygulanmıştır. Çalışmanın amacı, çevreyi koruma, geri dönüşüm, tüketim alışkanlıkları ve yaşam alışkanlıkları alt boyutları kapsamında çocukların çevreye yönelik tutumlarının araştırılmasıdır. Çalışmanın bulguları, okul öncesi dönem çocukları için hazırlanan bu çevre eğitim programının çocukların çevreye yönelik tutumlarında, tüm alt boyutları kapsayacak şekilde herhangi bir değişikliğe etkisinin olmadığını ortaya koymuştur. Bu sonucun ağırlıklı olarak, uygulanan eğitim programının süresinin kısıtlı olması ya da öğretmenlerin çevre eğitim programını destekleyici eğitim uygulamaları konusundaki yetersizliği ile açıklanabileceği belirtilmiştir.

Çalışma kapsamında elde edilen bulgular doğrultusunda ileride yapılacak olan çalışmalarda, çocukların çevreyi korumaları, geri dönüşümle ilgili derinlemesine bilgi edinmeleri, tüketim ve yaşam alışkanlıklarını çevreye verebilecekleri zararı düşünerek sürdürebilmeleri için farklı çevre eğitim programları hazırlanmalıdır. Hazırlanan bu çevre eğitim programlarında çocukların etkinliklerin her aşamasında aktif katılımlarının sağlanmasına ve yaparak yaşayarak öğrenmelerinin desteklenmesine önem verilmelidir. Hazırlanan çevre eğitim programlarının etkili bir şekilde uygulanabilmesi bakımından öğrenme ortamının amaca uygun bir şekilde hazırlanması da önem taşımaktadır ( Ergazaki, Zogza, ve Grekou, 2012). Ayrıca, çocuklarla birlikte yürütülecek olan bu projelerin eğitim süresi dört hafta ile sınırlandırılmayıp, minimum sekiz hafta devam eden projeler şeklinde yürütülmesi önerilmektedir. Bununla birlikte, çocuklarda çevre ile ilgili farkındalık ya da davranış değişikliği oluşturulmasında, ailenin önemli ve etkili bir rolü olduğu hatırlanarak, çevre eğitim programlarının uygulanmasında aile katılımı sağlanarak çalışmalar sürdürülebilir (Şallı vd., 2013).

\section{Makalenin Bilimdeki Konumu}

Temel Eğitim/Okul Öncesi Öğretmenliği

\section{Makalenin Bilimdeki Özgünlüğü}


Alan yazın incelendiğinde çevre eğitimi ile ilgili deneysel çalışmaların ağırlıklı olarak ilköğretim ve ortaöğretim seviyelerinde yapıldığ́ görülmüştür. Çevre eğitimi ile ilgili okul öncesi dönem çocukları ile yapılan deneysel çalışmaların sınırlı olması, özellikle çevre eğitim programlarının informal (okul dışı) eğitim ortamlarında uygulanması ve bu programların etkililiğinin araştırılması çok fazla araştırmaya konu olmamıştır. Bu nedenle, okul öncesi dönem çocuklarına okul dişı öğrenme ortamlarında uygulanan çevre eğitimi programı ile çocukların çevreye yönelik tutumları, çevreyi koruma, geri dönüşüm, tüketim alışkanlıkları ve yaşam alışkanlıkları alt boyutları ele alınarak, bu programının çocukların çevreye yönelik tutumları üzerindeki etkileri araştırılmıştır.

\section{Kaynaklar}

Aktaş-Arnas, Y. (2019). (Ed.). Çocuk merkezli ögrrenme ortamları: Okul öncesi çocuklar için bir okul tasarla. Ankara: Pegem Akademi.

Allen, R., Allaby, M., Davoll, J. \& Lawrence, S. (1972). A blueprint for survival. The Ecologist, 2(1), 1-43.

Basile, C. G. (2000). Environmental education as a catalyst for transfer of learning in young children. The Journal of Environmental Education, 32, 21-27.

Başal, H. A. (2015). Okul öncesi ve ilköğretim çocukları için uygulamalı çevre e ğitimi. Ankara: Nobel Akademi Yayıncılik.

Bonnet, M. \& Williams, J. (1998). Environmental education and primary children's attitudes towards nature and the environment. Cambridge Journal of Education, 28(2), 159-174.

Boyes, E. \& Stanisstreet, M. (1993). The 'greenhouse effect': Children's perceptions of causes, consequences and cures. International Journal of Science Education, 15, 531-552.

Carson, R. (1956). The sense of wonder. New York: Harper \& Row.

Carson, R. (1962). Silent spring. Boston: Houghton Mifflin.

Cohen, S. (1994). Children's environmental knowledge. (Ed. R. Wilson). Environmental education at the early childhood level (pp.19-22). Troy, OH: North American Association for Environmental Education.

Diamond, J. (2011). Collapse: How societies choose to fail or succeed, London, UK: Penguin Group.

Dilek-Eren, C. (2014). Çevre bilinci. (Ed. O. Bozkurt). Çevre Ĕgitimi (s. 179-213). Ankara: Pegem Akademi. 
Dresner, M. \& Gill, M. (1994). Environmental education at summer nature camp. Journal of Environmental Education, 25(3), 35-41

Ellul, J. (1964). The technological society. New York: Vintage Book.

Erdoğan, M. (2011). Ekoloji temelli yaz doğa eğitimi programının çocukların çevreye yönelik bilgi, duyuşsal eğilimler ve sorumlu davranışlarına etkisi. Kuramdan Uygulamaya Eğitim Bilimleri, 11(4), 2223-2237.

Erdoğan, M., ve Erentay, M. (2007). Children's perceptions on endangered species and threatened environments: Results from Unique and Universal Project. (Eds. M.F. Costa, B.V. Dorrío ve R. Reis). Development, Diversity and Inclusion in Science Education. (s. 141-148). Portugal: The Hands on Science Network.

Erdogan, M., Erentay, N., Barss, M., ve Nechita, A. (2008). Students' awareness of endangered species and threatened environments: A comparative case-study. International Journal of Hands-on Science, 1(2), 46-53.

Erdoğan, M., ve Misırlı, A. (2007). Graduate students' perspectives on the human-environment relationship. Journal of Turkish Science Education, 4(2), 21-30.

Erdoğan, M., ve Uşak, M. (2009). Curricular and extra-curricular activities for developing environmental awareness of young students: A case from Turkey, Odgojne ZnanostiEducational Sciences, 11(1), 73-85.

Ergazak1, M., Zogza, V., \& Grekou, A. (2009). From preschoolers' ideas about decomposition, domestic garbage fate and recycling to the objectives of a constructivist learning environment in this context. Rewiew of Math, Science and ICT Education, 3(1), 99-121.

Falk, J. H. (2001). Free-choice science learning: Framing the discussion. ( Ed. H. Falk). Freechoice science education: How we learn science outside of school. New York, NY: Teachers College Press.

Grodzinska-Jurzcak, M., Stepska, A., Nieszporek, K., \& Bryda, G. (2006). Perception of environmental problems among pre-school children in Poland. International Research in Geographical and Environmental Education, 15(1), 62-76.

Gunderson, R. (2014). Eric Fromm's Ecological messianism: The first biophilia hypothesis as humanistic social theory. Humanity \& Society, 38(2), 182-204.

Gülay, H. (2011). Ağaç yaş iken eğilir: Yaşamın ilk yıllarında çevre eğitiminin önemi. Türk Bilim Araştırma Vakfi, 4(3), 240-245.

Gülay, H., ve Ekici, G. (2010). MEB okul öncesi eğitim programı'nın çevre eğitimi açısından analizi. Türk Fen Eğitimi Dergisi, 7, 1, 74-84. 
Gülay, H., Yılmaz, Ş., Turan Güllaç, E., ve Önder, A. (2010). The effect of soil education project on pre-school children. Educational Research and Review, 5(11), 703-711.

Gülay-Ogelman, H. (2012). Teaching preschool children about nature: A project to provide soil education for children in Turkey. Early Childhood Education Journal, 40, 177-185.

Gülay-Ogelman, H., ve Durkan, N. (2014). Toprakla buluşan çocuklar: Küçük çocuklar için toprak eğitimi projesinin etkililiği. Uluslararası Sosyal Araştırmalar Dergisi, 7(31), 632- 638.Handler, D., \& Epstein, A. (2010). Nature education in preschool. Extensions Curriculum Newsletter from Highscope, 25(2), 1-7.

Heimlich, J. E. (2010). Environmental education evaluation: Reinterpreting education as a strategy for meeting mission. Evaluation and Program Planning, 33(2), 180-185.

Karasar, N. (2000). Bilimsel araştırma yöntemi. Ankara: Nobel Yayınevi.

Keleş, R. ve Hamamcı C. (1993), Çevrebilim Ankara: İmge Kitabevi.

Matthews, B.E., \& Riley, C.K. (1995). Teaching and evaluating outdoor ethics education programs. Vienna, VA: National Wildlife Federation.

Otto, S., \& Kaiser, F.G. (2014). Ecological behavior across the lifespan: Why environmentalism increases as people grow older. Journal of Environmental Psychology, 40, 331-338.

Otto, S., Kaiser, F.G., \& Arnold, O. (2014). The critical challenge of climate change for psychology: Preventing rebound and promoting more individual irrationality. European Psychologist, 19, 96-106.

Özdemir, O. (2010). The effects of nature-based environmental education on environmental perception and behavior of primary school students. Pamukkale University Journal of Education, 27, 125-138.

Özdemir, O., ve Uzun, N. (2006). Yeşil sınıf modeline göre yürütülen fen ve doğa etkinliklerinin ana sınıfı öğrencilerinin çevre algılarına etkisi. Çocuk Gelişimi ve Ĕ̆itim Dergisi, 1(2), 12-20.

Potter, G. (2010). Environmental education for the 21st century: Where do we go now? The Journal of Environmental Education, 41(1), 22-33.

Russo, S. (2001) Promoting attitudes towards environmental education depends on early childhood education. Australian Primary and Junior Science Journal, 17(4), 34-36.

Smith, A. (2001). Early childhood a wonderful time for science learning. Australian Primary and Junior Science Journal, 17(2), 18-20. 
Solomon, E. P., \& Heide, K. M. (2005). The biology of trauma: Implications for treatment. Journal of Interpersonal Violence, 20, 51-60.

Sonnenfeld, D., Mol, A., 2002. Globalization and the transformation of environmental governance. American Behavioral Scientist, 45(9), 1318-1339.

Starosta, B. (1990). Discoveries in living nature according to the principle of learning by discovery: Didactic concepts and results of an empirical study. (Eds. W. Killermann, ve L. Staeck). Methods of biology education (pp. 316-326). Germany: Aulis-Verlag.

Stevenson, R. B., Brody, M., Dillon, J., \& Wals, A. E. J. (Eds.) (2013). International handbook of research on environmental education. New York: Routledge.

Stone, S. J., \& Glascott, K. (1998). The affective side of science instruction. Childhood Education, 74, 102-104.

Şahin-Pekmez, E., Yılmaz H. ve Kahveci, C. (2010). Influence of learning science in outdoor settings on 5th grade students' understanding of the nature of science. Paper presented at the 7th International Conference on Hands-on Science. Rethymno-Crete.

Şallı, D. (2011). Proje tabanlı ögrenme yaklaşımı ile 48-60 aylık çocuklara geri dönüşüm kavramının kazandırılması. Yüksek Lisans Tezi. Sosyal Bilimler Enstitüsü Marmara Üniversitesi, İstanbul.

Şallı, D., Dağal, A. B., Küçükoğlu, E. K., Niran, S. Ş., ve Tezcan, G. (2013). Okul öncesinde geri dönüşüm kavramı: Aile katılımlı proje tabanlı bir program örneği. Eğitim ve Öğretim Araştırmaları Dergisi, 2(2), 234-241.

Taşkın, O., ve Şahin, B. (2008). Environment concept and six-year-old preschool children. Pamukkale University, Journal of Faculty of Education, 23(1), 1-14.

Temiz, Z., Karaarslan-Semiz' G., \& Y1lmaz, S. (2018) "Nasreddin Hodja and walnut tree”. A Turkish Indigenous Story about Human-Nature Interaction. In Aghasaleh, R., Children and mother nature, storytelling for a glocalized environmental pedagogy. Sense Publishers: Boston.

Turtle, C., Convery I. , \& Convery, K. (2015). Forest schools and environmental attitudes: A case study of children aged 8-11 years. Cogent Education, 2(1), 1100103.

Wells, N.M., \& K.S. Lekies. (2006). Nature and the life course: Pathways from childhood nature experiences to adult environmentalism. Children, Youth \& Environments, 16, 1, $1-24$. 
Wilson, R.A. (1993). Fostering a sense of wonder during the early childhood years, Columbus Ohio: Greyden Press.

Wilson, R. A. (1996). Environmental education programs for preschool children. Journal of Environmental Education, 27(4), 71-81.

Yılmaz, S., Temiz, Z., \& Karaarslan-Semiz, G. (2018). Children's understanding of humannature interaction after a folk storytelling session. Applied Environmental Education \& Communication, 19(1), 88-100.

\section{Summary}

\section{Statement of Problem}

In today's world, due to the rapid population growth and technological advances, children are born into a world where there is a global warming, a reduction in biodiversity and natural food supply, soil erosion, a shortage of energy and water, and many other environmental problems that threaten both the health of people and nature (Diamond, 2011; Gunderson, 2014). According to Koger (2013), the main source of these problems is human behaviors. Both human beings and technologies of human occupation lead to serious environmental problems. This fact leads to the questioning of the existing production and consumption systems.

Several studies (ex., The Ecologist's Blueprint of Survival, 1972; Small is Beautiful, 1974) and reports (ex., The Limits to Growth, 1972; Our Common Future, 1987) have pioneered for taking steps both to address the seriousness of environmental problems and give noteworthy warnings about the possible solutions for them (Keleş and Hamamc1, 1993). There studies and reports highlighted that there is a need for developing both environmental policies without human interest and taking educational, legal, and technological initiatives.

Several researchers (e.g., Grodzinska-Jurzcak, Stepska, Nieszporek and Bryda, 2006; Taşkın and Şahin, 2008) asserted that individuals' attitudes, skills, and knowledge about environment begin to develop from early childhood years and, which in turn, affect their environmental behaviors in a long run. It is possible to say that the development of generations growing up high environmental awareness, and environmental sensitivity which is effective for environmental protection can be achieved through the implementation of well-planned and continuous early childhood environmental education programs (Potter, 2010; Wells and Lekies, 2006). 
According to Handler and Epstein (2015), children need to access free natural environments to sustain natural awareness which is developed in early childhood period. In particular, informal educational environments can contribute to develop children's environmental awareness (Erdoğan and Uşak, 2009), environmental consciousness (Erdoğan and Misirl1, 2007), and environmental responsibility (Matthews and Riley, 1995), which in turn developing positive attitudes and behaviors toward environment (Dresner and Gill, 1994). In recent years, carrying out environmental education to informal out-of-school educational environments such as, parks, museums, zoos, aquariums, forests/woodlands, and nature centers has been gained importance (Aktaş-Arnas, 2019; Heimlich, 2010). Environmental education programs in such kind of environments are seen more appealing since they allow children discover the environment and gain variety of experiences (Falk, 2001).

Educational studies investigating the effects of environmental education programs in informal out-of-school settings mainly conducted in either elementary or secondary education levels. These studies emphasized the positive impacts of such kind of programs on children's positive perceptions, attitudes and behaviors since they offer children hands-on learning opportunities (Erdoğan and Erentay, 2007; Erdoğan, 2011; Erdoğan, Erentay, Barss and Nechita, 2008; Özdemir, 2010; Pekmez, Y1lmaz and Kahveci, 2010; Starosta, 1990).

Studies exploring the effects of environmental education programs on children in an early childhood level have also been conducted by several authors (Gülay, Y1lmaz, Turan Güllaç and Önder, 2010; Gülay-Ogelman, 2012; Gülay-Ogelman and Durkan, 2014; Özdemir and Uzun, 2006; Şallı, 2011; Şallı, Dağal, Küçükoğlu, Niran and Tezcan ,2013; Tanrıverdi, 2012; Yalçın 2013). These studies are mostly designed as quasi-experimental research. Also, considering the gap in the literature, there is a need for the implementation of environmental education programs in informal out-of-school settings.

Therefore, this study aims to investigate children's attitudes toward environment in preschool level. In order to reach that aim the main research question is determined as following: Is there a statistically significant difference between children's environmental attitudes scores after attending the environmental education program?

\section{Method}

The purpose of this research was to investigate preschool children's attitudes toward environment, including environmental protection, recycle, consumption habits, and living 
habits. The participants of the research were 71 60-moth-old children. The equity of children's gender was considered by the researchers $\left(\mathrm{n}_{1=34}, \mathrm{n}_{2}=37\right)$. These children were randomly selected from public preschools and kindergartens affiliated to Ministry of National Education in Mersin. With regard to the data collecting material, 'The Children's Attitudes toward the Environment Scale-Preschool Version, (CATES-PV)' was used as a valid and reliable measurement to collect the data (Cronbach alpha $=.68$ ). The data collecting material included 15 interview questions. One-to-one interviews were applied with each of the participating children individually. Children were asked about their ideas about the pictures which are shown them in accordance with the interview questions. Children's responses were recorded and transcribed for the data analysis. There was a two data collecting process during this research. First of all, the researchers asked the interview questions before the implementation of the environmental education program as a pre-test. Each participating child had an interview after the implementation of the educational program. Regarding the details of the environmental education training, there were a four-week educational program which is held in different outdoor settings, such as a worm farm, a national park, waste disposal and recycling facility). The researchers arranged field trips once a week with each group of children and educators. The environmental education program was implemented by taking children's active participation and hands on experiences into attention in these fields.

\section{Findings and Discussion}

According to the results, there was no statistically significant difference in children's pre-test and post-test scores on environmental attitudes in terms of recycle, environmental protection, consumption habits and living habits. The $p$ values for each sub-dimension of the scale were .60, .39, .74, and .22, respectively. According to Gülay (2011), environmental education programs could have an impact on children's attitudes and behaviors either in a short or long run. Therefore, the reason why environmental education program does not affect children's attitudes toward environment could be explained by the limitation of time of the program. Therefore, considering it should take a long time to make a difference in children's attitudes and behaviors in early years, continuously implemented environmental education should be an inseparable part of early childhood education programs. In addition, the result of the study could be expressed by the limited number of the activities to develop children's attitudes toward environment in terms of environmental protection, recycle, consumption and living habits (Gülay-Ogelman and Durkan, 2014; Şallı et al., 2013). 


\section{Conclusion and Suggestions}

Since the four-week environmental education program did not have impact on children's attitudes toward environment, further research should be planned considering the length of the education program. Also, different environmental education programs which children can actively participate in learning activities should be designed to make a difference in children's attitudes toward environment. 